\title{
NAIL AND GRAFT ARTHRODESIS OF THE HIP
}

\author{
T. B. Gardiner, Glasgow, Scotland
}

From the Department of Orthopaedic Surgery, University of Glasgow

The treatment of osteoarthritis of the hip is still a highly controversial subject, but in Great Britain most orthopaedic surgeons would agree that a sound bony fusion of the joint in good position is the most uniformly successful procedure for severe unilateral osteoarthritis of the hip in a patient under fifty years of age. Arthrodesis of the hip would undoubtedly be more popular in older patients if: 1) fusion could be obtained with greater certainty; 2) the operative technique could be simplified; and 3) the prolonged period of post-operative immobilisation could be avoided, with its attendant expense and discomfort, and the risk of permanent loss of movement in the knee of the affected side.

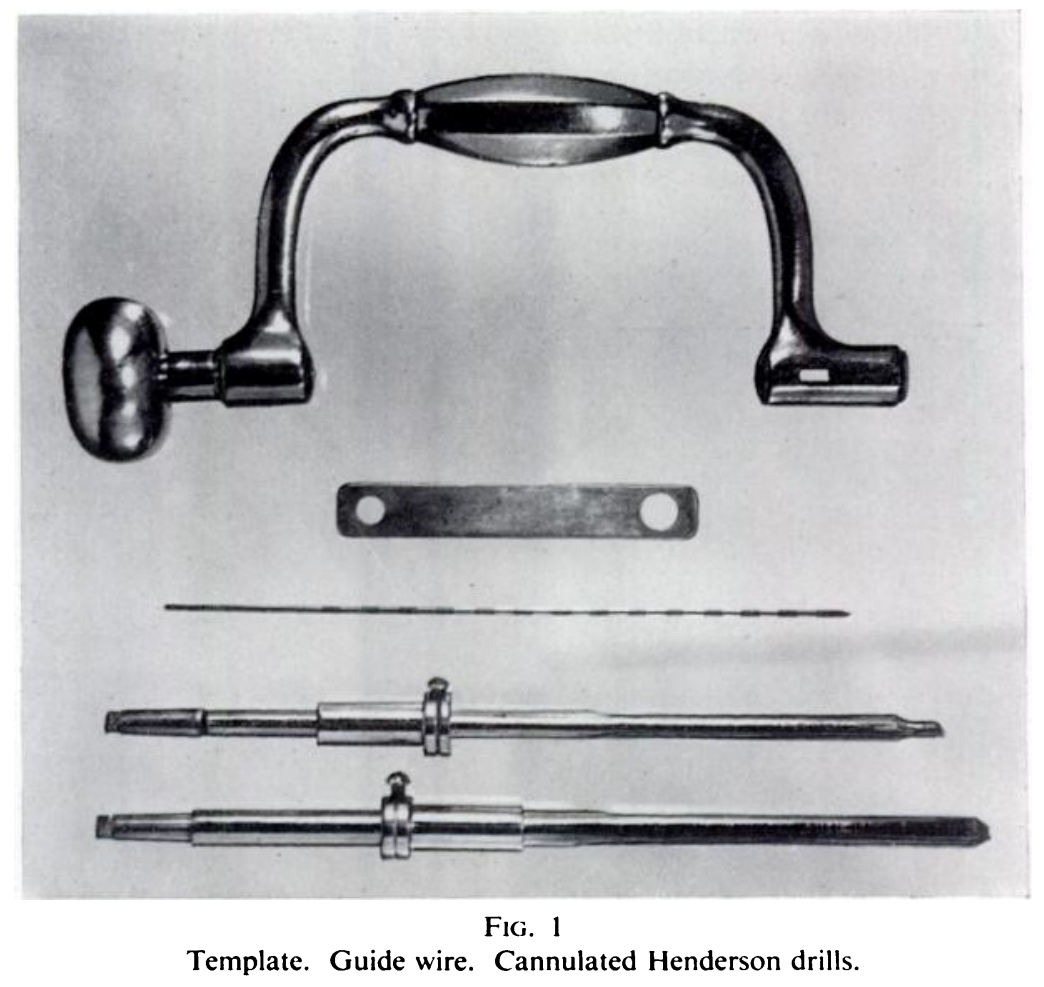

This paper is written to revive interest in the procedure described by Brittain (1952) under the title of "V-arthrodesis" of the hip. He stated that a satisfactory fusion was obtained in thirty-six of the forty patients operated on over a period of three years. It is evident from the illustrations in his monograph that not all thirty-six patients obtained a sound bony fusion, and this could hardly be expected having regard to the short period of follow-up.

In the Orthopaedic Department of the Glasgow Western Infirmary a similar operation has been practised for the past nine years, except that we have used a full-thickness fibular graft in preference to one from the crest of the tibia. This paper is a report of the results of the operation in fifty-three patients who have been followed up for a minimum of one year. 


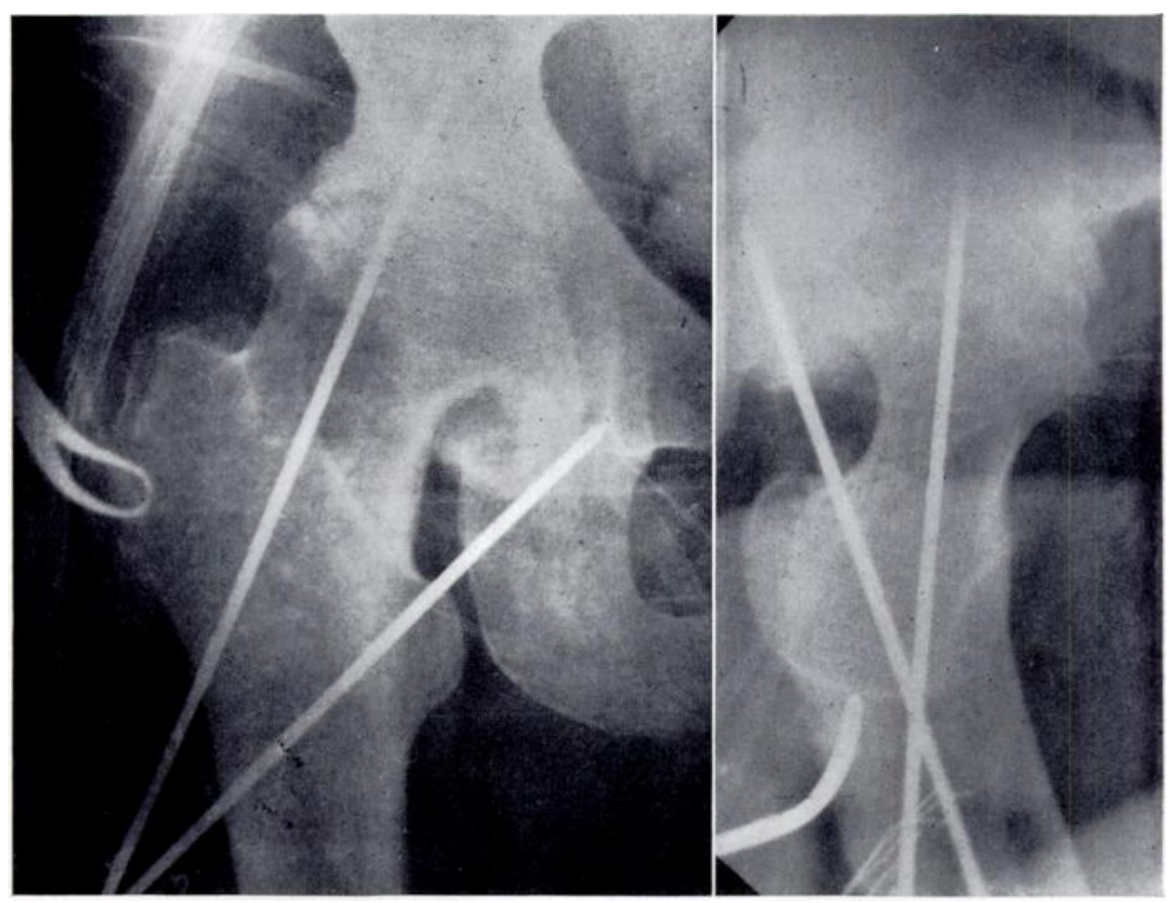

FIG. 2

Radiographs showing position of guide wires.

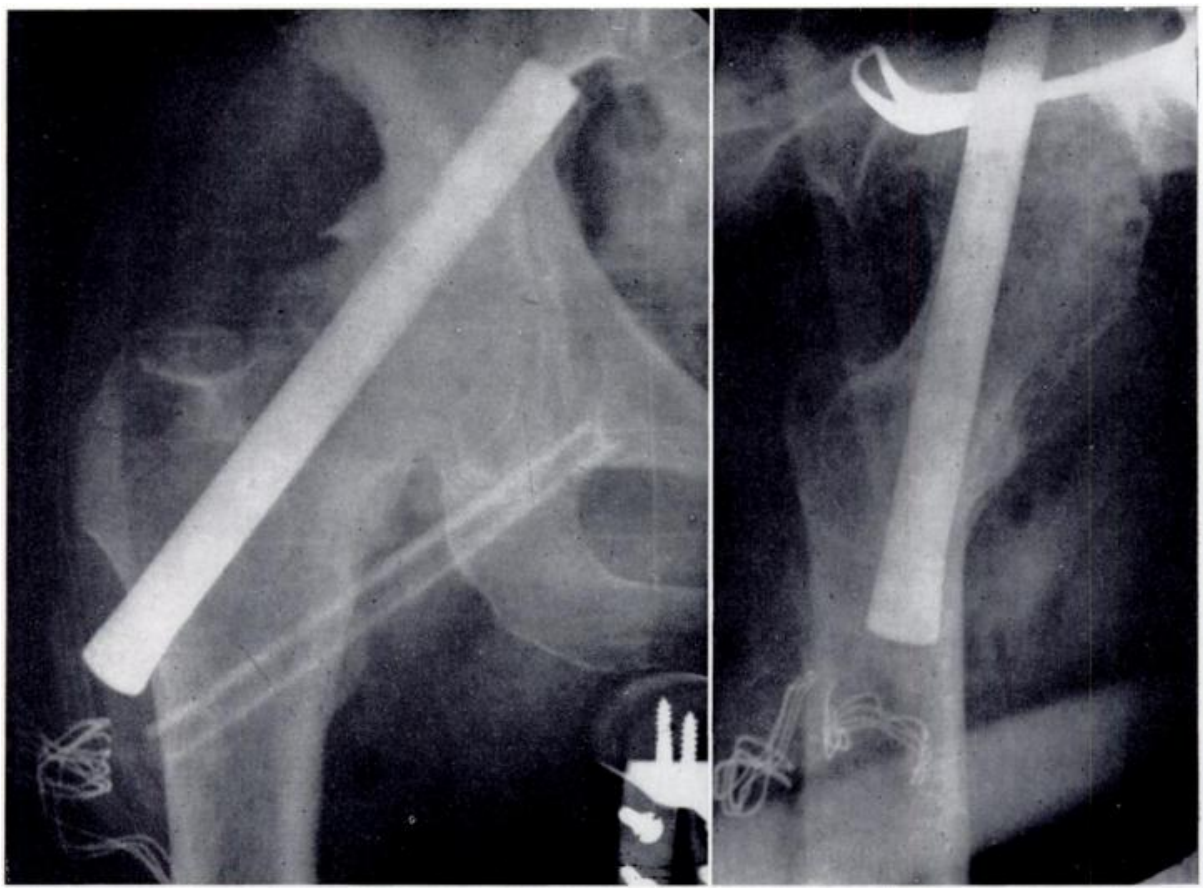

FiG. 3

Radiographs showing Smith-Petersen nail and graft inserted.

VOL. 44 B, No. 3, AUGUST 1962 
The operation has been performed by all members of the staff of the department, and has gradually become the procedure of election in the following circumstances. 1) The opposite hip should be normal or show only minimal osteoarthritic changes. 2) It is particularly suitable for elderly patients who are severely crippled and have only limited movement of the hip. 3) It must be possible to correct a severe flexion and adduction contracture of the hip if this is present. A fixed lateral rotation deformity is of less importance. It is impossible to determine by clinical and radiographic examination if the deformity can be corrected, but under anaesthesia and with a suitable muscle relaxant there is seldom any difficulty in obtaining an acceptable position. For preference the position of 30 degrees of flexion and slight adduction is chosen. This gives a better gait than any other position, and is preferred even if a raise on the shoe is required to compensate for shortening.

\section{TECHNIQUE OF OPERATION}

The operation is simple. It imposes no greater strain on an elderly patient than the nailing of a femoral neck fracture, and is well within the compass of any surgeon who is familiar with this operation. If necessary the hip is manipulated, and the patient is placed on a suitable

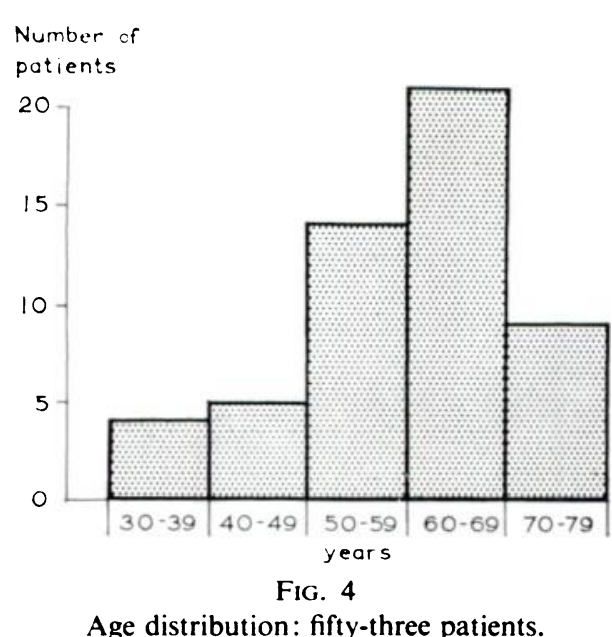

Age distribution: fifty-three patients. fracture table with the hip in the desired position. The lateral aspect of the shaft of the femur immediately below the trochanter is exposed and two guide wires are inserted under radiographic control. The upper guide wire is passed through the cortex about half an inch below the attachment of the vastus lateralis to the base of the trochanter, and is directed towards the weightbearing surface of the femoral head, and then onwards for another inch or so into the ilium. It should be placed slightly behind the axis of the neck of the femur in the lateral projection so as to engage the thick buttress of bone deep to the hip joint. The lower guide wire is inserted at a point three-quarters of an inch below the first and is directed towards the lesser trochanter, and on a plane about 30 degrees posterior to the first guide.

After penetrating the medial cortex of the femur the guide wire is passed on until it encounters the ischium immediately below the lower margin of the acetabulum (Fig. 2), and on into the bone for a further inch. A Smith-Petersen nail is then driven in over the upper guide wire. Its length should permit insertion into the ilium to a depth of about one inch. While the radiographs are being processed, a suitable length, as determined from the lower guide wire, of the middle third of the fibula of the same leg is excised. The graft is trimmed until it is roughly circular in shape and will just pass through one of the two holes in the template (Fig. 1). These holes are half an inch and three-eighths of an inch in diameter. The larger one is chosen for preference. A cannulated Henderson drill (Fig. 1) of the same diameter as the graft is then passed over the lower guide wire and a drill hole is made through the femur and on into the ischium to a depth of about one inch. The graft is then driven into position along this drill hole and firmly impacted into the ischium (Fig. 3). Recently a McLaughlin nail plate (Fig. 5) has been used in preference to a Smith-Petersen nail in an attempt to avoid the one serious complication during the post-operative period, namely fracture of the shaft of the femur at or immediately below the level of the graft. It seems likely to be successful. No plaster is applied after the operation, and partial weight bearing with crutches is encouraged as soon as the wounds are healed. 


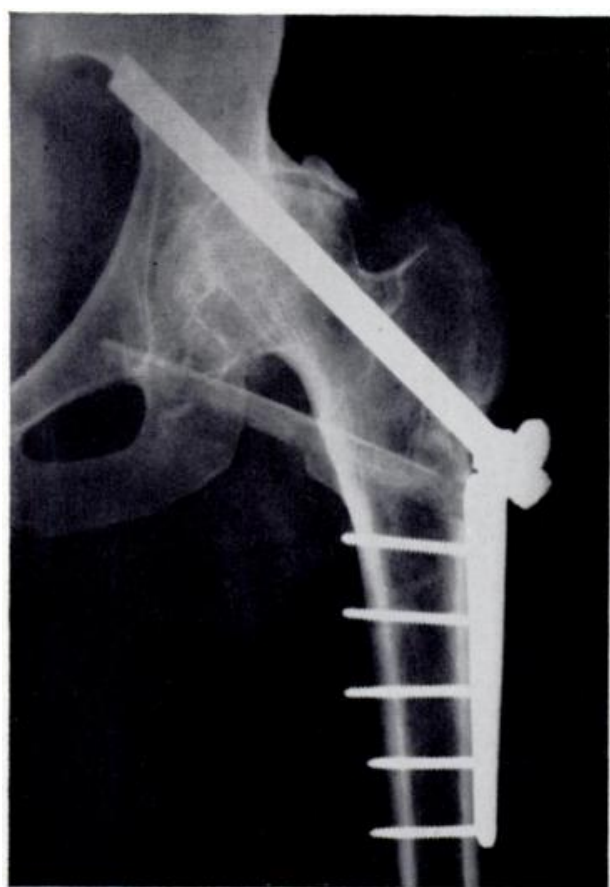

FIG. 5

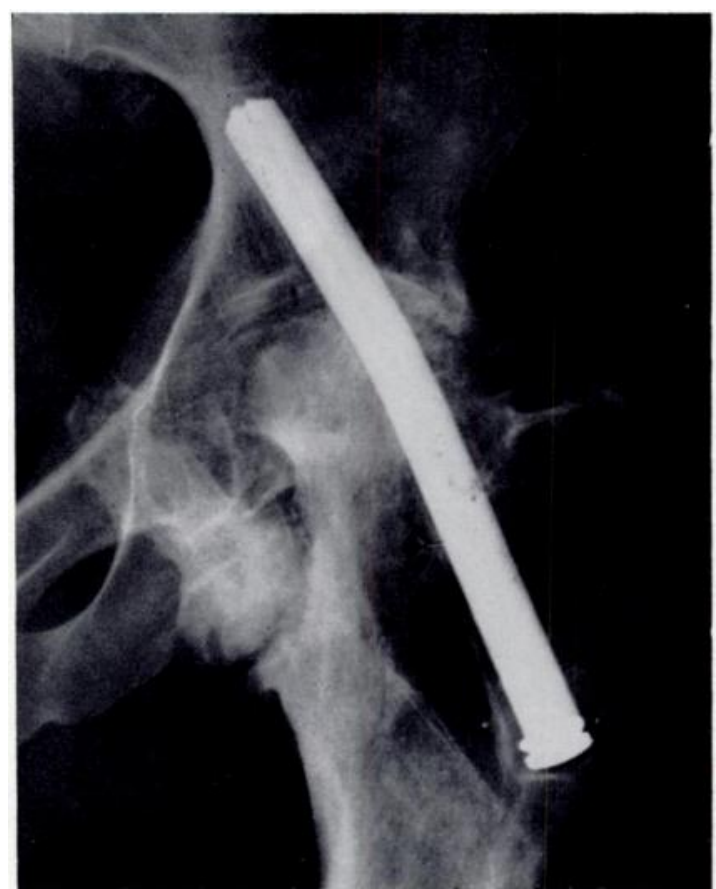

FIG. 6

Figure 5-Radiograph showing the McLaughlin nail plate and graft. Figure 6-Radiograph showing a pseudarthrosis in the graft.
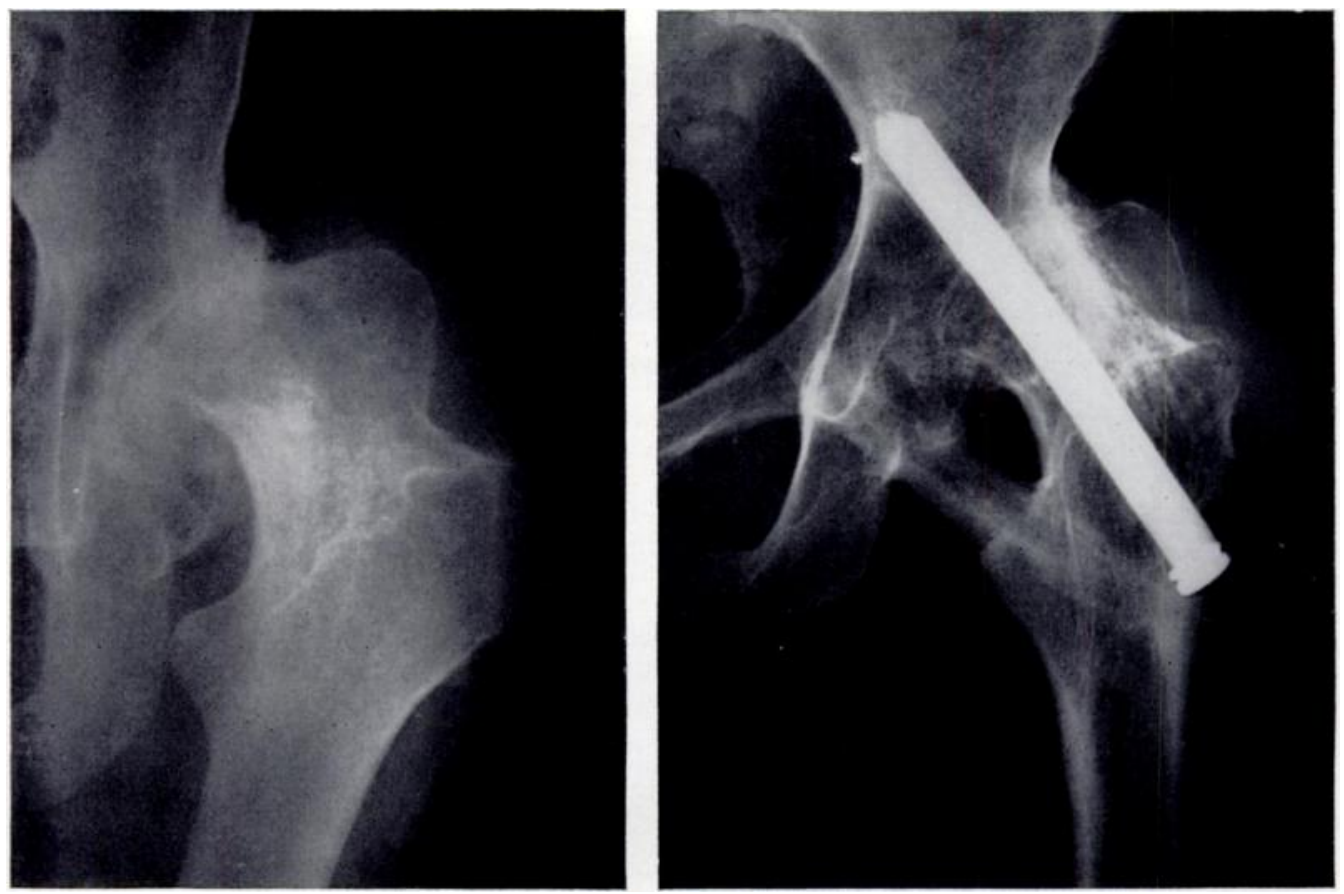

Fig. 7

Pre-operative and post-operative radiographs showing sound bony fusion.

vol. 44 B, No. 3, AUGUST 1962 


\section{RESULTS}

The ages of the patients operated on ranged from thirty to eighty years, the average age being sixty (Fig. 4). Four of the fifty-three patients died, a man of seventy-three immediately after operation from heart failure, a frail old lady of eighty within a few days of operation,
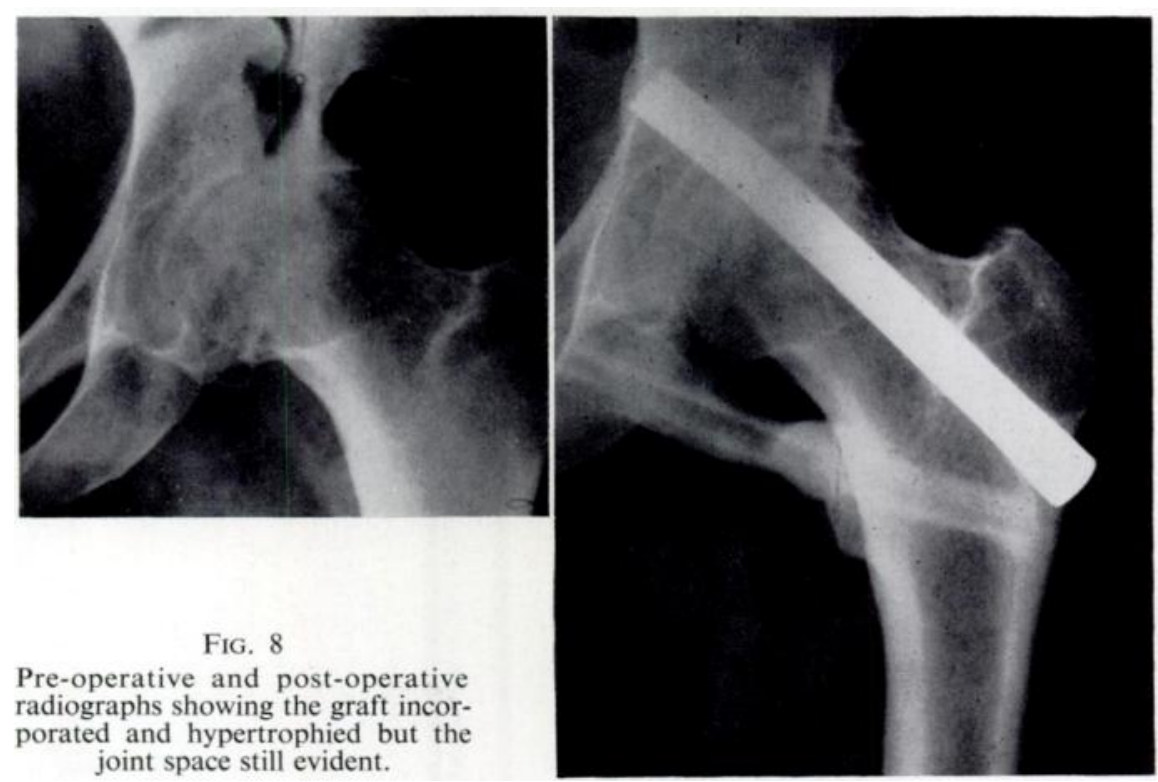

a man aged sixty-four from coronary thrombosis at two months, and a woman aged seventyfour one year after operation from cerebral thrombosis.

There have been three failures. In one case too short a graft was inserted and in two

Pre-operative and post-operative radiographs showing the graft incorporated and hypertrophied but the joint space still evident. others the graft fractured and the nail was extruded.

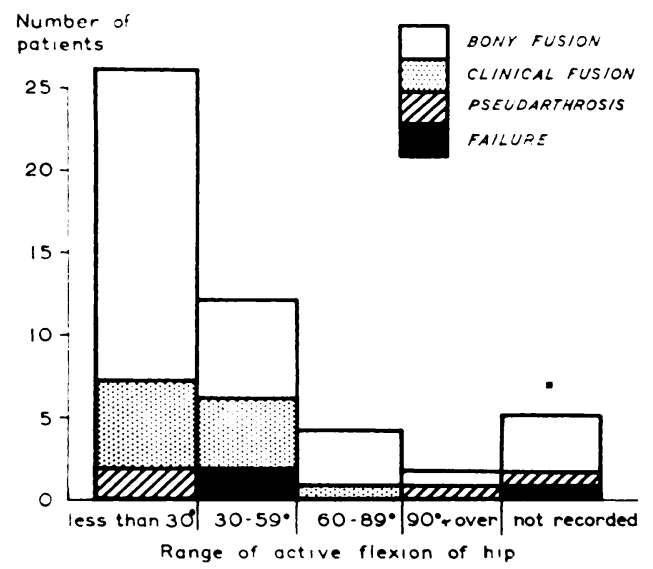

FIG. 9

Influence of range of flexion on fusion.
We have been unable to trace one forty-five-
year-old man since nine months after operation. but at that time the hip was clinically fused and he had returned to his employment as a lorry driver.

Four patients had a pseudarthrosis in the graft (Fig. 6) but no movement can be detected in the hip and they have no pain. (Fig. 7).

Thirty-two patients have sound bony fusion

In the remaining nine patients the graft is incorporated in the femur and ischium and there is no movement at the hip, but a joint space is still evident on radiographic examination (Fig. 8). In eight of these patients it is less than twentyseven months since operation.

It is evident that the rate of bony fusion improves with time. The influence of the range of hip flexion is shown in Figure 9. As expected, there was a high incidence of bony fusion at the time of follow-up when the range of active flexion in the hip was less than 30 degrees, but most hips fuse eventually and satisfactory results are obtained if the indications for the operation are carefully followed. 


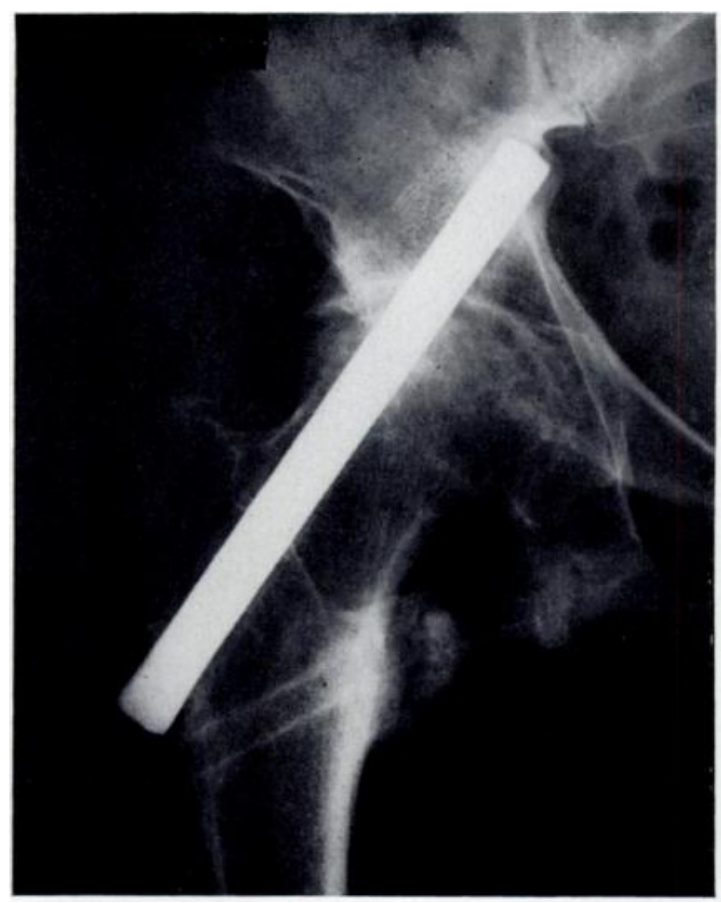

Fig. 10

Radiograph showing healed fractures of graft.

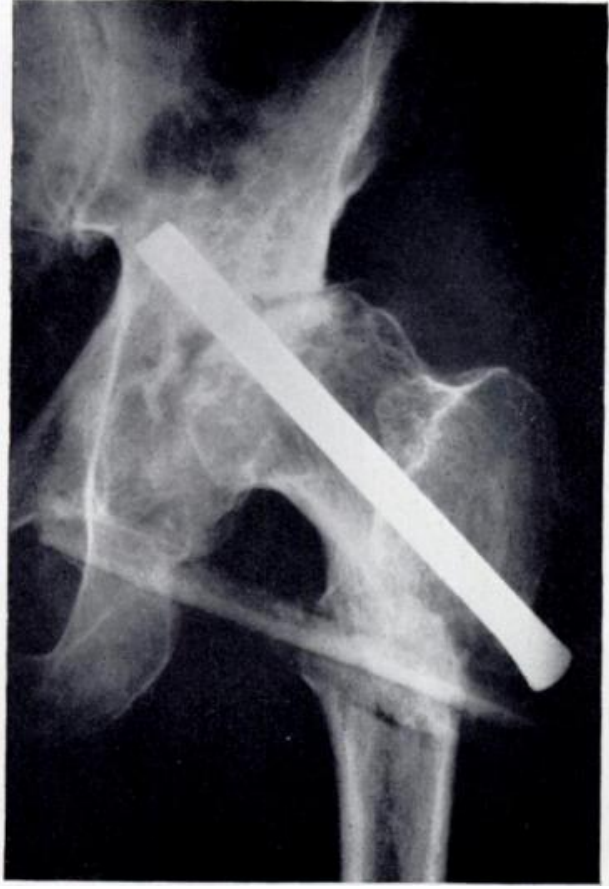

Fig. 11

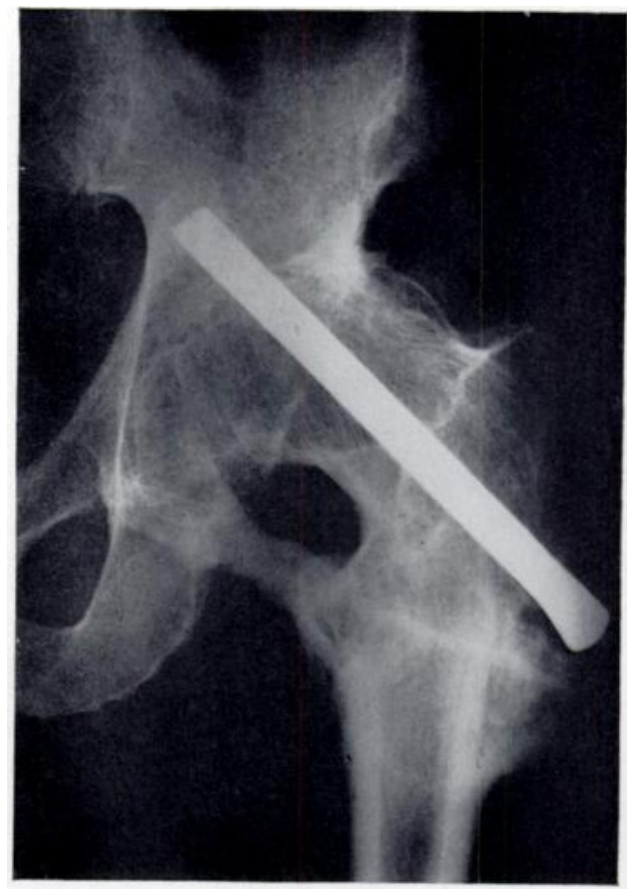

FIG. 12

Figure 11-Radiograph showing fracture of femur soon after operation. Figure 12-Radiograph showing femoral fracture united and sound bony fusion. 


\section{COMPLICATIONS}

The graft fractured on twelve occasions but in six patients it united without any special treatment (Fig. 10). In the remaining six cases two operations were failures and four patients developed a pseudarthrosis.

Seven patients sustained a fracture of the femur at the level of the graft, but all united after treatment (Figs. 11 and 12). In an endeavour to prevent this complication a McLaughlin nail plate has been used for the past two years (Fig. 5). Since then there has been only one fracture of the femur, in a patient who had a violent injury.

There have been no stiff knees. Only two patients, one of whom had a fracture of the femur, have less than 90 degrees of flexion in the joint.

Five patients developed a deep venous thrombosis after operation and one had a transient drop foot.

\section{SUMMARY AND CONCLUSIONS}

The Brittain V-arthrodesis is a satisfactory procedure for osteoarthritis of the hip. It is particularly suitable for elderly patients when the range of hip flexion is less than 60 degrees. If the four deaths are excluded, two-thirds of the patients secured a sound bony fusion. This occurs slowly. All but one of the patients who survived for three years or more after operation had a sound bony fusion. It is evident that the operation, given time, yields a high rate of sound bony fusion in the hip. It seems likely that use of the McLaughlin nail plate would prevent the one serious complication, namely fracture of the shaft of the femur through or immediately below the drill hole made for the fibular graft.

I wish to thank Professor Roland Barnes for his help and criticism and Mr Gabriel Donald for the illustrations.

REFERENCE

Britrain, H. A. (1952): Architectural Principles in Arthrodesis. Second edition. Edinburgh: E. \& S. Livingstone Ltd. 